In der Rubrik „Literatur kompakt" dieser Ausgabe referieren und kommentieren diese Experten für Sie Arbeiten aus der internationalen Fachliteratur.

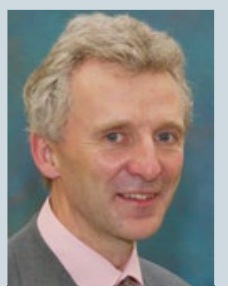

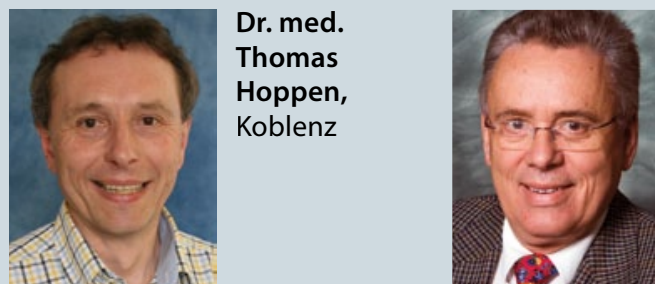

Dr. med. Hartmut Koch, Vechta

\title{
Neues Allergen in Milbenfäzes entdeckt
}

Gelegentlich reagieren Hausstauballergiker nicht auf die üblichen Hauptallergene der Hausstaubmilbe Der $p 1$ und Der $p$ 2. Ein österreichisches Team um Margit Weghofer aus Wien nahm daher an, dass noch weitere Hauptallergene bei Dermatophagoides (D.) pteronyssinus vorliegen müssten.

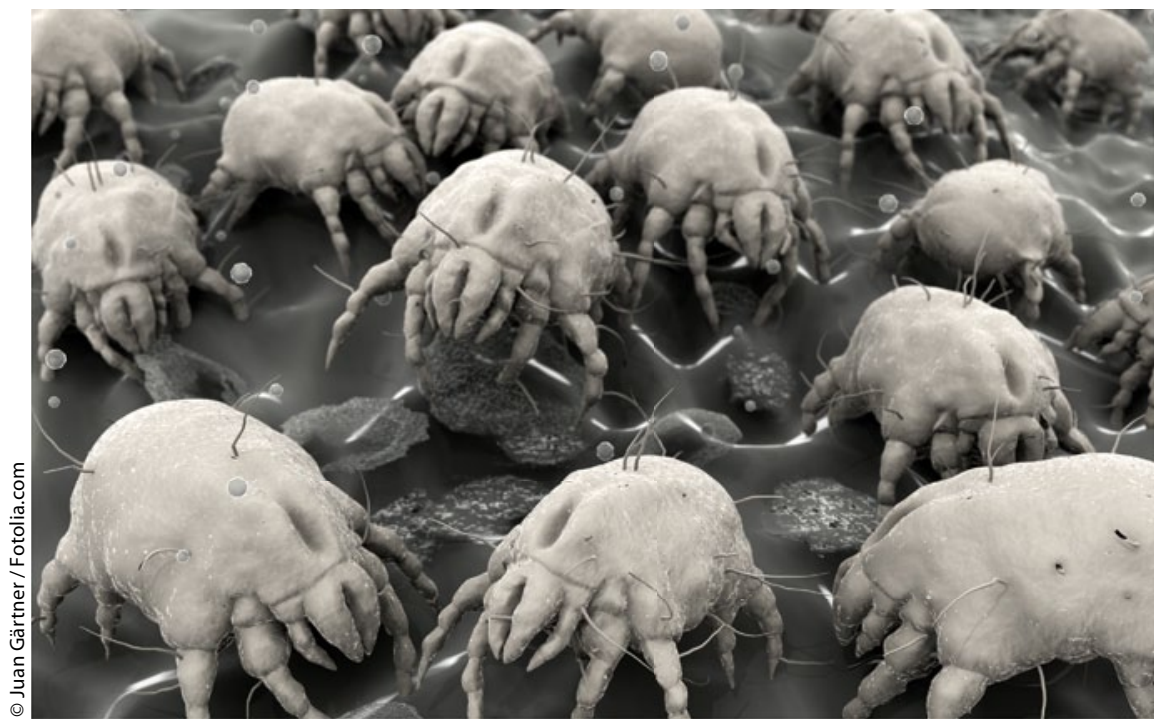

Scheiden mehrere Allergene aus: die Hausstaubmilbe Dermatophagoides pteronyssinus

ie International Union of Immunological Societies [UIS] benennt Allergene nach einer verbindlichen Nomenklatur aus drei Buchstaben am Anfang, gefolgt von einem weiteren Buchstaben und einer Zahl, die die Herkunft und klinische Wichtigkeit des Allergens reflektieren. Der $\mathrm{p} 1$ und Der $\mathrm{p} 2$ sind die klassischen Hauptallergene der Hausstaubmilbe. Wissenschaftler aus Österreich vermuteten jedoch, dass das noch nicht alles sein könnte. Deshalb untersuchten sie das Immunglobulin E (IgE) aus Seren von österreichischen, franzö- sischen und italienischen Patienten mit Hausstauballergie und setzten zusätzlich weitere gentechnische Verfahren ein.

Sie konnten ein bislang unbekanntes Antigen finden, das inzwischen von der UIS die Bezeichnung Der p 23 erhielt. Das neue Antigen wurde immunelektronenmikroskopisch in der peritrophen Matrix entlang des Mitteldarms von D. pteronyssinus und auf der Oberfläche von Kotballen der Milbe nachgewiesen.

Die Blutproben der Probanden enthielten auch tatsächlich zu 70-87\% allergenspezifisches IgE, damit dürfte
Der p 23 ebenfalls zu den Hauptallergenen der häufigsten Hausstaubmilbe in Europa zählen. Auch konnten die Wiener Kolleginnen zeigen, dass von $158 \mathrm{Se}$ ren von Patienten mit Hausstaubmilbenallergie sechs ausschließlich gegen dieses neue Antigen reagierten, nicht jedoch gegen Der $\mathrm{p} 1$, Der $\mathrm{p} 2$ sowie die bisher bekannten Der p 5, Der p 7, Der p 10 und Der $\mathrm{p} 21$.

Bei der Gegenprobe mit Blutproben von nicht-allergischen Probanden konnte kein spezifisches IgE gegen das neue Hausstaubmilbenantigen Der p 23 nachgewiesen werden. Und nicht nur beim IgE, sondern auch bei der Aktivierung basophiler Granulozyten (einem Verfahren zur Abschätzung der klinischen Wertigkeit von Allergenen) zeigte Der $p$ 23 sein hohes Allergiepotenzial: Einige Probanden zeigten dabei eine Aktivierung der Basophilen über dem Zehnfachen gegenüber Der $\mathrm{p} 1$.

Die Wissenschaftlerinnen sehen daher in Der p 23 (zusätzlich zu Der p 1 und Der p 2 ) ein zusätzliches und wichtiges Testantigen für die erweiterte Allergiediagnostik.

Weghofer $\mathrm{M}$ et al. Identification of Der p 23, a Peritrophin-like protein, as a new major Dermatophagoides pteronyssinus allergen associated with the peritrophic matrix of mite fecal pellets. J Immunol 2013;190: 3059-67

Kommentar: Weil Der p 23 mit durchschnittlich $79 \%$ recht stark mit IgE und auch signifikant mit einer Basophilenaktivierung reagiert, wäre es wahrscheinlich gut, dieses neu gefundene Allergen bei der Diagnostik und evtl. auch bei der zukünftigen Hyposensibilisierung (SLIT wie SCIT) bei Allergikern und sensibilisierten Asthmatikern einzusetzen - in Ergänzung zu Der $p 1$ und Der $\mathrm{p} 2$.

Dr. Ulrich Mutschler 